\title{
Amiodarone-Associated Optic Neuropathy
}

\author{
Sara Weidmayer, OD, FAAO \\ Staff Optometrist, \\ VA Ann Arbor \\ Healthcare System; \\ Clinical Assistant Professor, \\ University of Michigan's \\ Department of Ophthalmology \\ and Visual Sciences
}

\begin{abstract}
A 72-year old male presented symptomatic for unilateral inferior visual field loss, but was found to have bilateral optic neuropathy. Clinical features, an extended minimally symptomatic course and a temporal relationship to amiodarone use implicated amiodarone-associated optic neuropathy. Serial ancillary testing analyses provided insight into this entity's natural course. This patient developed the greatest retinal nerve fiber layer thinning in the inferior quadrant; this may correlate with anatomically larger-diameter axons, supporting a previous publication which suggested that larger-diameter optic nerve axons are more susceptible to amiodarone-induced lipidosis. While rare, amiodaroneassociated optic neuropathy may develop and cause permanent loss of visual function.
\end{abstract}

\section{KEYWORDS}

amiodarone, optic neuropathy, optic disc edema, toxic optic neuropathy, anterior ischemic optic neuropathy 


\section{INTRODUCTION}

Amiodarone-associated optic neuropathy has been reported in $1.79 \%$ of amiodarone users. ${ }^{1}$ However, the most recent critical review of this entity, in 2012, identified fewer than 300 cases reported, with only 59 published, and only a small number of case reports have been published since. ${ }^{2}$ This case adds to the small body of literature which details the course of amiodarone-associated optic neuropathy, supports its diagnosis as a distinct clinical entity, and provides comprehensive serial photographs, optical coherence tomography and the results of visual field analyses. These findings provide insight into the natural course of amiodarone-associated optic neuropathy.

\section{CASE REPORT}

A 72 year-old white male presented as a new patient reporting a dark arc-shaped scotoma in the bottom portion of the right eye's vision. He had initially reported this to his clinical pharmacist about 2 months previously. He denied headaches, jaw claudication, temporal tenderness, transient visual obscurations, nausea, vomiting, fever, malaise and diplopia. His last eye exam had been 5 years previously and was reported as unremarkable.

His medical history included diverticulitis, esophageal reflux, colonic polyps, herpes simplex 1, degenerative joint disease, congestive heart failure and atrial fibrillation. Six months previously, the patient had been hospitalized for progressive shortness of breath with left leg edema due to atrial fibrillation with rapid ventricular response. He was given an intravenous loading dose of amiodarone for 24 hours, then 400 mg twice per day for 10 days, and was discharged on $200 \mathrm{mg}$ daily. He was also taking bumetanidine $3 \mathrm{mg}$ daily, metoprolol $37.5 \mathrm{mg}$ daily, omeprazole $20 \mathrm{mg}$ daily, polyethylene glycol powder daily and warfarin (3 mg on Mondays, Wednesdays and Fridays and $2 \mathrm{mg}$ on Tuesdays, Thursdays, Saturdays and Sundays). His social and family history were non-contributory.

His best corrected acuity was 20/40 in the right eye and 20/25 in the left eye. He had a mild right afferent pupillary defect. Other initial findings and anterior segment exam were non-contributory. On dilated fundus exam, the right eye had a cup-to-disc ratio of $0.15 / 0.15$ with a sector of neuroretinal rim pallor superotemporally, and the inferior half of the disc was edematous. There were disc hemorrhages inferonasally and superonasally (Figure $1 A$ ). The left eye had no appreciable cupping with a diffusely edematous disc and disc hemorrhages nasally and temporally (Figure $1 B$ ). His blood pressure in clinic was 116/75 with a regular pulse rate of 71 beats per minute. Visual field showed a moderate inferior arcuate defect with a few depressed superior edge points in the right eye, and superior and inferior arcuate defects in the left eye (Figures 2 and 3). Optical coherence tomography retinal nerve fiber layer analysis using a Cirrus device (Carl Zeiss, Oberkochen, Germany) showed superior thinning in the right eye, with an overall average thickness of $70 \mu \mathrm{m}$. The left optic disc's neuroretinal rim and retinal nerve fiber layer were grossly elevated, with an average thickness of $154 \mu \mathrm{m}$.

The main differential diagnoses at that time included papilledema; bilateral versus sequential anterior ischemic optic neuropathy, either arteritic or non-arteritic; and amiodarone-associated optic neuropathy.

He was initially evaluated emergently by computed tomography without contrast, and then later evaluated by magnetic resonance imaging of the brain and orbits, both with and without contrast, and by magnetic resonance venography. The results were normal with no evidence of a space-occupying lesion, or secondary radiologic signs of increased intracranial pressure or dural venous sinus thrombosis. The patient's complete blood count was normal, platelets were normal $\left(256 \times 10^{3} / \mu \mathrm{L}\right.$, reference range $\left.130-400 \times 10^{3} / \mu \mathrm{L}\right)$, C-reactive protein was elevated $(1.305 \mathrm{mg} / \mathrm{dL}$, reference range $0-0.748 \mathrm{mg} / \mathrm{dL})$ and the Westergren erythrocyte sedimentation rate was mildly elevated $(23 \mathrm{~mm} /$ hour, reference range $0-15 \mathrm{~mm} /$ hour $)$, though the clinical picture was not suggestive of giant cell arteritis. At that time, the most likely differential diagnoses became bilateral versus sequential non-arteritic anterior ischemic optic neuropathy and amiodarone-induced optic neuropathy.

The patient was followed-up at 4 weeks, with no changes in his health or medication history in the interim; his visual symptomatology was stable in the right eye, and he remained asymptomatic in the left eye. He again denied headaches, temporal tenderness and jaw claudication. His vision was pinholed to 20/50 right eye, 20/30- left eye. Dilated fundus exam of the right eye still showed an edematous inferior disc margin and superotemporal pallor, but the disc hemorrhage had resolved (Figure 1C). The left optic nerve was still diffusely edematous with a disc hemorrhage temporally (Figure $1 D$ ). His visual field indicated a deeper inferior arcuate defect, with worsened 
sensitivity of several points and worsened mean and pattern standard deviation, with a few scattered superonasal rim defects in the right eye (Figure 2); the left eye showed an incomplete inferior arcuate defect with a cluster of defects superonasally, which was slightly improved in both hemifields (Figure 3). The retinal nerve fiber layer by optical coherence tomography was stable in the right eye, and still grossly elevated, but with an average thickness of $-31 \mu \mathrm{m}(123 \mu \mathrm{m})$ in the left eye compared to previously.

Figure 1: Serial optic nerve photographs of the right (top panel) and left (bottom panel) eyes. Initial presentation: (A) right eye showing superotemporal pallor, inferior disc edema, and inferonasal and superonasal hemorrhages; (B) left eye showing diffuse disc edema and nasal and temporal hemorrhages. At 1 month: (C) right eye showing superotemporal pallor, inferior disc edema with the resolution of disc hemorrhages but an intraretinal hemorrhage superior to the disc; (D) left eye showing diffuse edema and a disc hemorrhage nasally. At 2 months: (E) right eye showing superotemporal pallor, inferior edema; (F) left eye showing diffuse disc edema and a disc hemorrhage nasally. At 2.5 months: $(G)$ right eye showing stable superotemporal pallor and inferior edema; (H) left eye showing diffuse disc edema without hemorrhaging. At 6 months: (I) right eye showing superotemporal pallor and resolution of the inferior disc edema; (J) left eye with disc edema clinically resolved. At 8 months: $(K)$ right and $(L)$ left eyes are clinically stable. At 18 months: $(M)$ right and $(N)$ left eyes remain clinically stable.

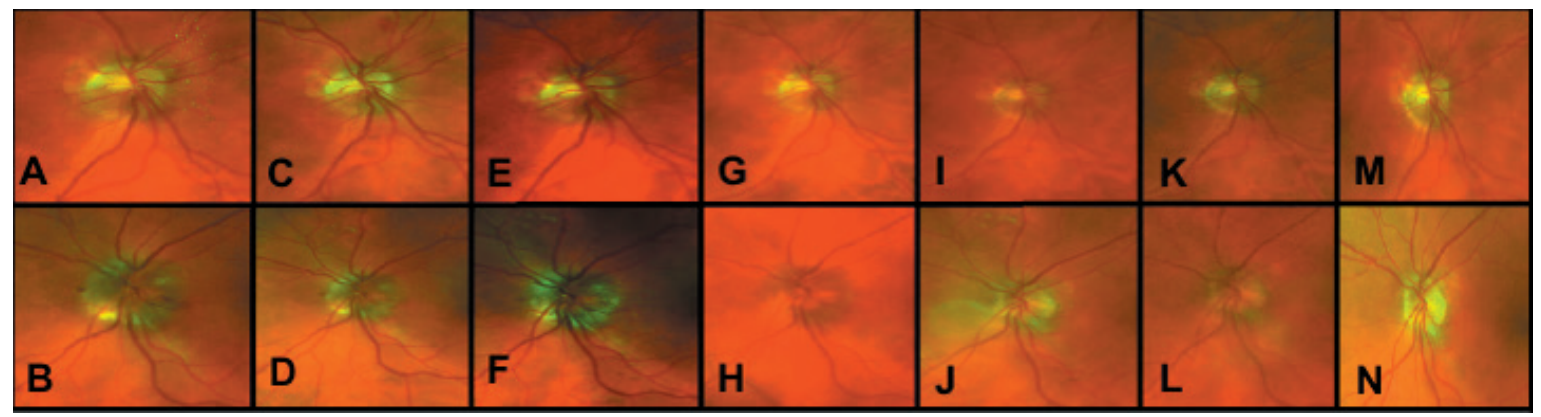

After consultation with the patient's cardiologist and clinical pharmacist, given that the patient's electrocardiogram readings since amiodarone initiation had shown normal sinus rhythm and the patient was anticoagulated with warfarin, the choice was made to discontinue amiodarone and follow-up closely with cardiology.

Over the subsequent weeks and months, the patient was routinely followed-up with serial dilated fundus exams, photographs, visual field exams and optical coherence tomography. Over that time, laboratory testing of the erythrocyte sedimentation rate and C-reactive protein down-trended, complete blood counts and platelets remained normal, hemoglobin Alc was normal at 5.9\%, and rapid plasma reagin syphilis screening was non-reactive. His acuity ultimately stabilized at 20/30 in the right eye, which represented an improvement of about 1 line of Snellen acuity, and 20/25 in the left eye, which was roughly stable compared to the initial presentation.

The optic disc edema in both eyes resolved clinically at 6 months, leaving associated atrophy that corresponded to retinal nerve fiber layer thinning on optical coherence tomography. Progression analysis of the retinal nerve fiber layer clearly indicated stability in the area where pallor had been evident on presentation (superotemporally) in the right eye, but showed progressive thinning inferiorly as the edema resolved. Similarly, diffuse progressive retinal nerve fiber layer thinning over the clinical course was visualized in the left eye. Though the disc edema had resolved clinically at 6 months in both eyes, additional retinal nerve fiber layer thinning in the left eye was evident at 8 months on optical coherence tomography (Figures 4 and 5, Table 1). Visual fields ultimately stayed relatively stable in both eyes (Figures 2 and 3, Table 2). His clinical evaluation at 18 months was stable relative to the 8-month evaluation (Figure 1). Amiodarone-associated optic neuropathy was strongly implicated in this case. 
Figure 2: Serial visual fields of the right eye. Visual field of the right eye at (from top down) the initial presentation, and after 1, 2, 4 and 8 months showing an inferior arcuate defect and a small cluster of superocentral edge defects, which remained relatively stable and permanent throughout the clinical course.

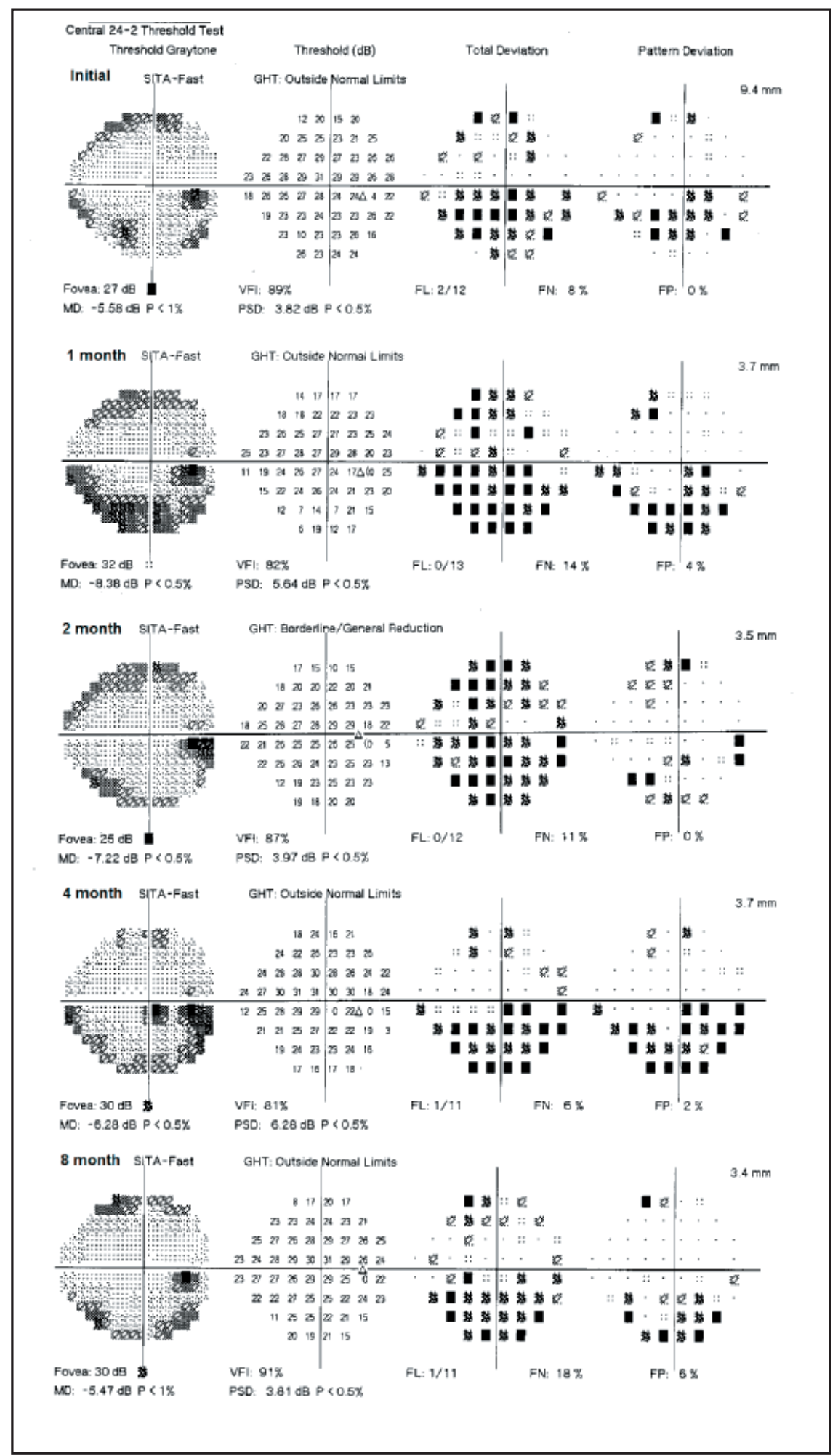


Figure 3: Serial visual fields of the left eye. Visual field of the left eye at (from top down) the initial presentation, and after 1, 2,4 , and 8 months showing superior and inferior arcuate defects, which remained relatively stable and permanent throughout the clinical course.

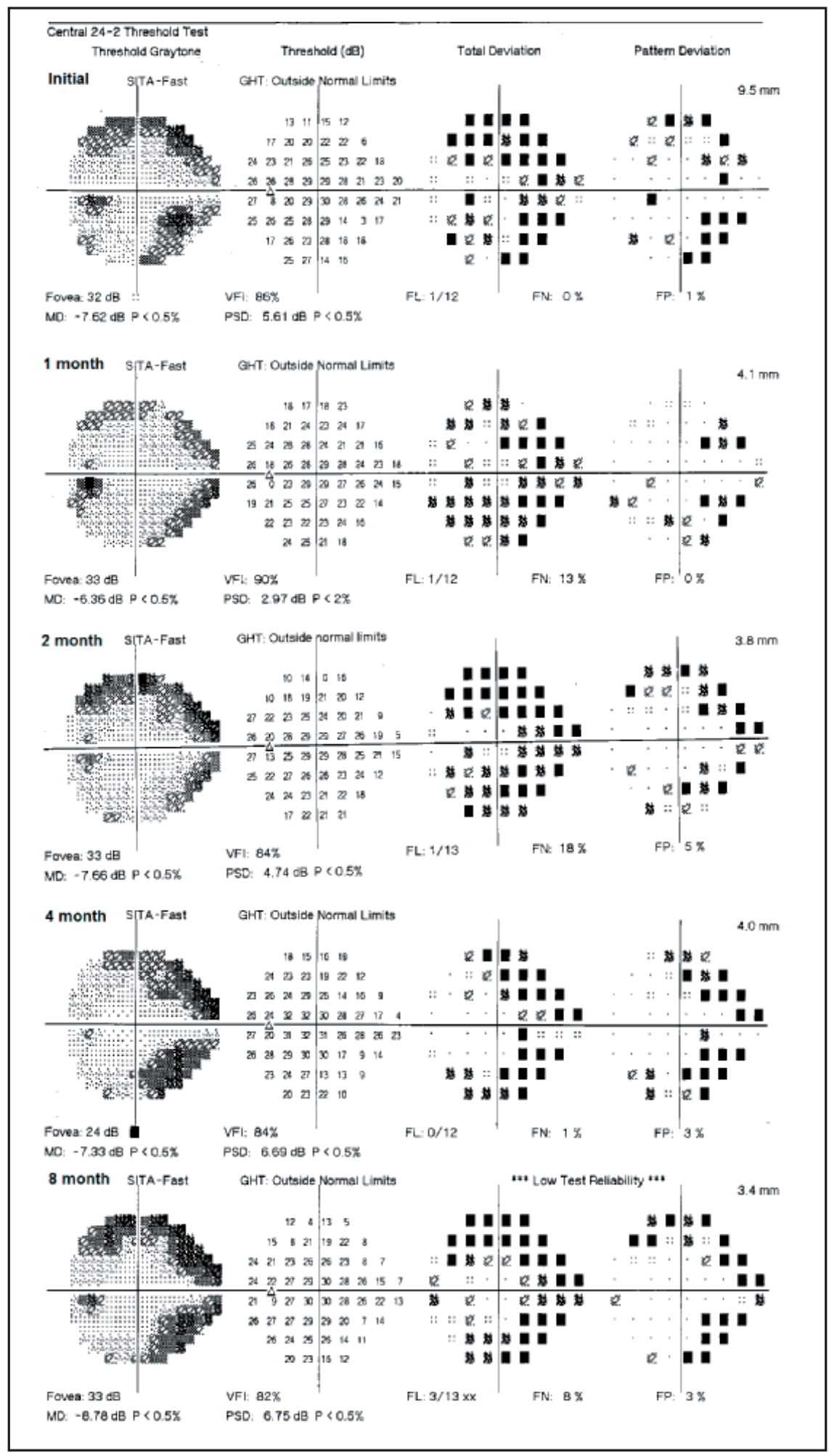


Figure 4: Retinal nerve fiber layer (RNFL) thickness progression analysis of the right eye using Zeiss Cirrus optical coherence tomography. Retinal nerve fiber layer thickness progression analysis from (left to right) the initial visit and after 1, 2, 4, 6 and 8 months showing stable superior retinal nerve fiber layer thickness, but progressive inferior thinning over the clinical course.

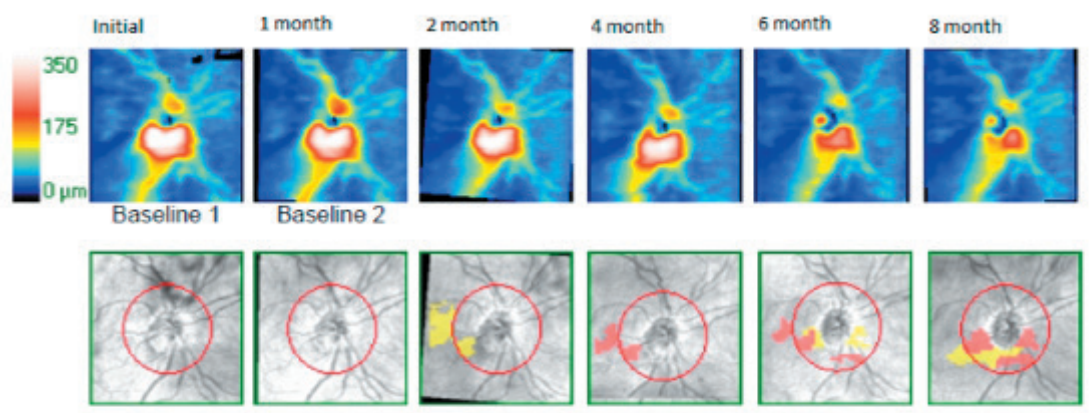

Average RNFL Thickness

RNFL Thickness Profiles

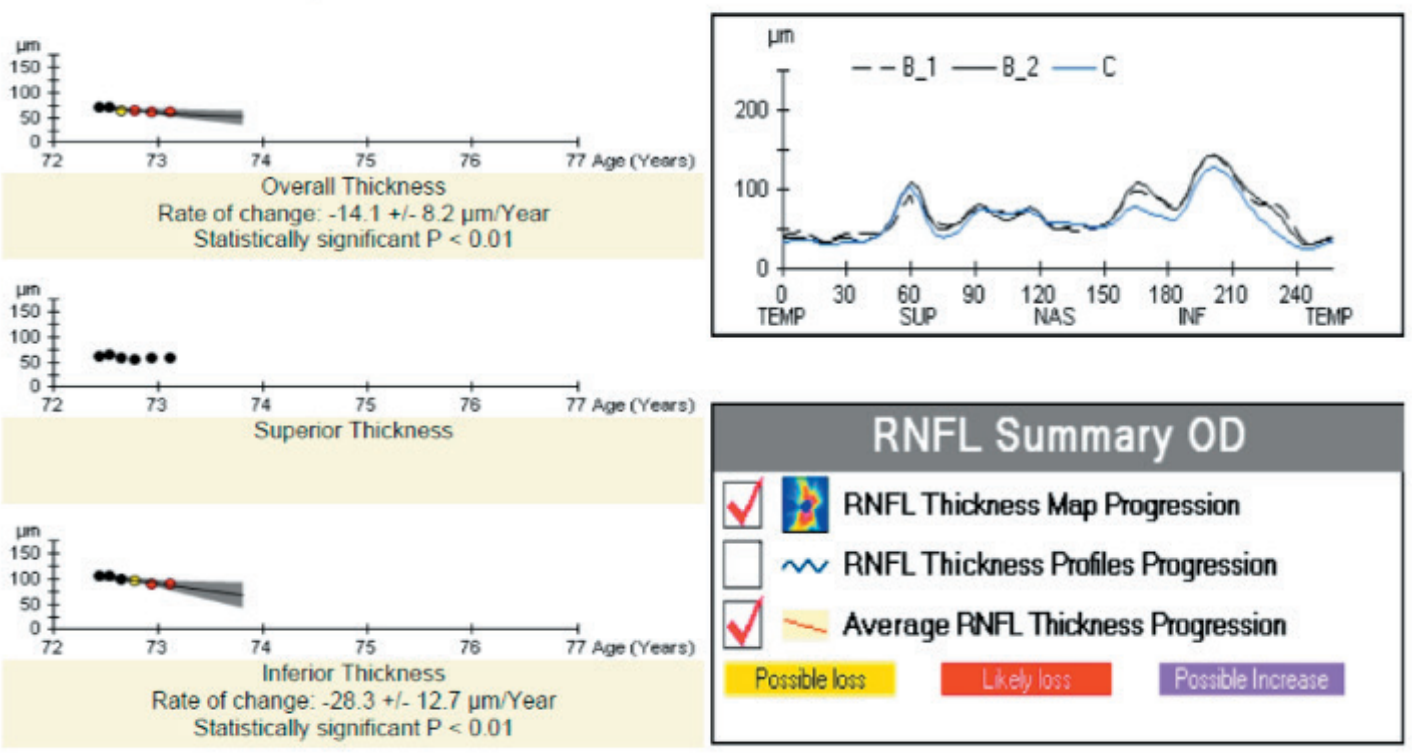

DISCUSSION

Amiodarone is a widely used and efficacious cardiac anti-arrhythmic benzofuran derivative ${ }^{3-5}$ that can result in toxicity to several organs including the eyes, liver, lungs, nervous system, thyroid and skin..$^{6-8}$ Many amiodarone users experience side effects, ${ }^{9}$ around $15 \%$ by 1 year and $50 \%$ by 5 years, ${ }^{10}$ nearly $20 \%$ of which are serious or significant and may necessitate discontinuation. ${ }^{11}$

Ocular involvement is typically isolated to corneal micro-deposits (verticillata), which are a well-established, dosedependent amiodarone-induced keratopathy seen in $70-100 \%$ of amiodarone users. ${ }^{3}$ These are benign, but in some cases can cause halo vision, glare or photosensitivity. ${ }^{5,9}$ Opacities in the anterior subcapsular lens may also form. ${ }^{12}$ These both generally occur 6.5 weeks or later after the initiation of amiodarone, ${ }^{5}$ are non-threatening and generally not bothersome to patients. Corneal verticillata are due to amiodarone-induced lipodosis. ${ }^{8}$ Amiodarone is very lipophilic and can similarly deposit into tissues throughout the body, ${ }^{8,13}$ slow nerve conduction velocity, ${ }^{8}$ and lead to other documented secondary problems systemically. ${ }^{4,8,13}$ Amiodarone-associated optic neuropathy was first identified in 1987 and can cause visual devastation, including permanent vision loss. ${ }^{1,2,12-19}$ The pathophysiology of its development is not yet fully established; however, ischemia secondary to mechanical or biochemical hindering of axoplasmic flow due to the accumulation of intracytoplasmic lamellar inclusion bodies, a drug-induced lipidosis, ${ }^{4}$ particularly in large optic nerve axons, has been implicated. ${ }^{20}$ 
Figure 5: Retinal nerve fiber layer (RNFL) thickness progression analysis of the left eye using Zeiss Cirrus optical coherence tomography. Retinal nerve fiber layer thickness progression analysis from (left to right) the initial visit and after 1, 2, 4, 6 and 8 months showing retinal nerve fiber layer thinning in all quadrants over the clinical course.

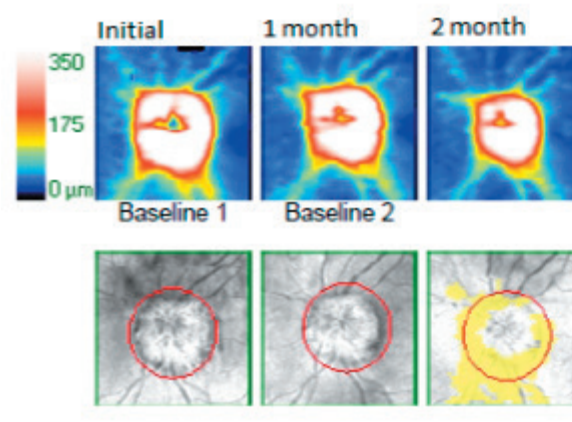

Average RNFL Thickness
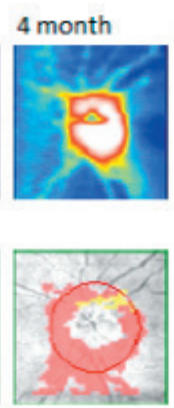

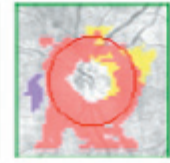

8 month
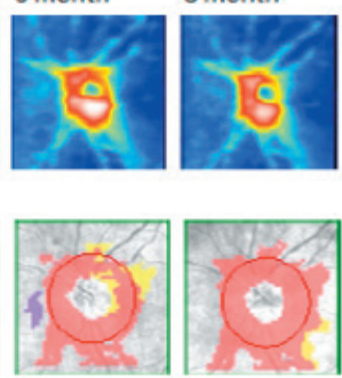

RNFL Thickness Profiles

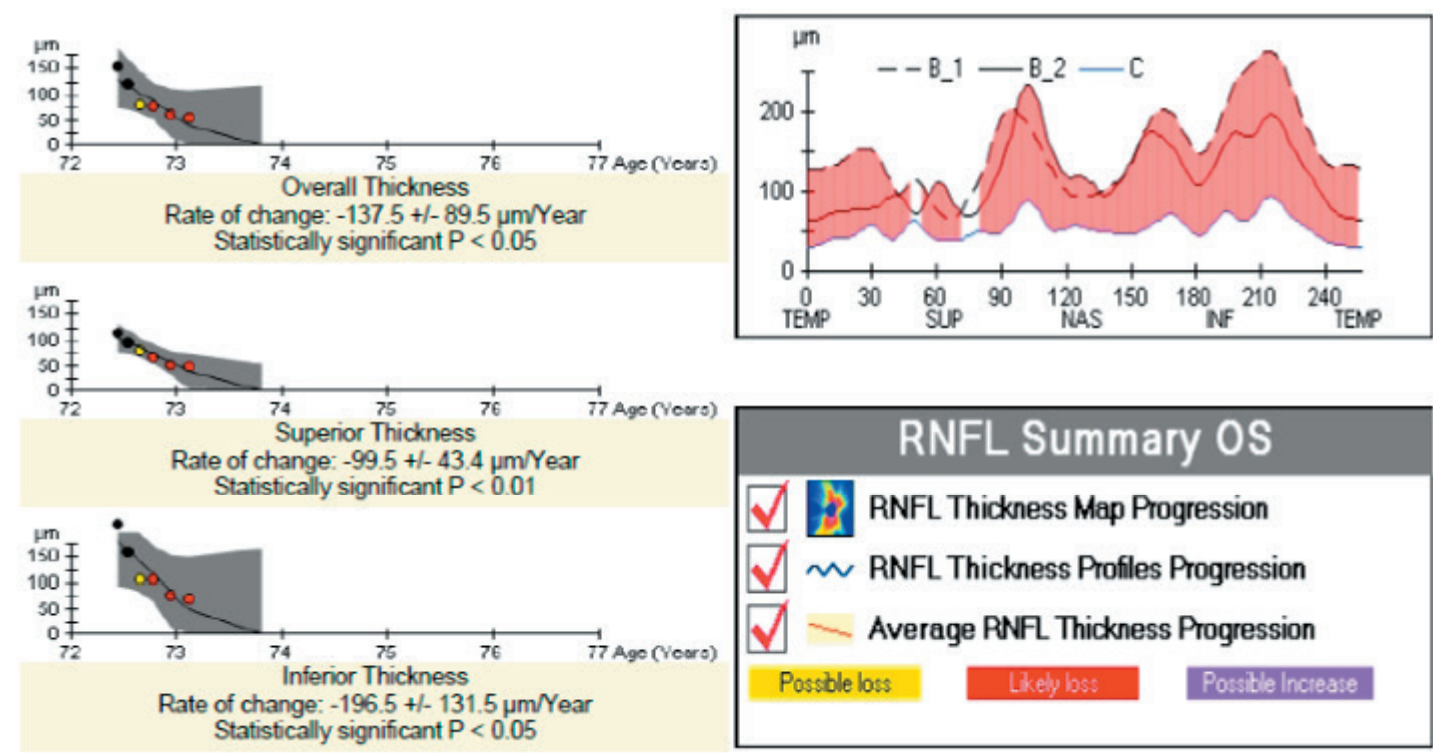

Even though corneal verticillata is the most common ocular sequelae of amiodarone use, and this patient did not exhibit verticillata, its absence does not preclude the diagnosis of amiodarone-associated optic neuropathy. In support of this statement, Johnson et al presented a case series and review and found that amiodarone-associated optic neuropathy developed within six months of initiating amiodarone therapy for 19 of 35 (54\%) patients who had amiodarone keratopathy and 13 of 18 (72\%) of patients without amiodarone keratopathy. The authors further stated, "Consequently, patients with amiodarone-associated optic neuropathy may not exhibit corneal verticillate, particularly since the median duration of amiodarone use in patients with vision loss is four months. Hence, absence of amiodarone keratopathy should not dissuade clinicians from establishing the diagnosis of amiodarone-associated optic neuropathy." ${ }^{21}$

Reported cases and cumulative reviews of amiodarone-associated optic neuropathy indicate that it generally occurs simultaneously bilaterally (around 66\%) 2,22 $^{2}$ and most often shows an insidious onset with slowly progressive visual symptoms over months, ${ }^{2,18,22,23}$ associated with optic disc edema and subsequent atrophy. ${ }^{2,23,24}$ Nearly $90 \%$ of those affected develop clinical manifestations of optic neuropathy within 12 months, ${ }^{18}$ with symptoms of vision loss occurring at a mean of 9 months and a median of about 3-4 months after drug initiation; ;,18,25 however, optic neuropathy has been reported as early as 3-4 weeks after intravenous or oral amiodarone administration. ${ }^{13,14}$ Acuity at presentation may range from 20/15 to light perception, with nearly $20 \%$ having acuity of $20 / 200$ or worse. ${ }^{2,18}$ While it may present with acute vision loss, $13 \%$ to nearly $30 \%$ of patients may be asymptomatic, even with clinically evident optic neuropathy. ${ }^{2,18}$ Visual field deficits vary, but tend to 
be relatively mild and may include centrocecal scotomas, mild peripheral defects, generalized constriction or altitudinal defects. ${ }^{8,18,24}$ This characterization of insidious onset with slow, bilateral progression and prolonged optic disc edema progressing to atrophy was first described by Macaluso et al., and later echoed by subsequent reports, case series and reviews. ${ }^{8,17,22,23}$ However, cases may deviate from this generalization and can present with acute vision loss or unilateral optic neuropathy. ${ }^{18}$ Stabilization of the optic disc with resolution of edema tends not to occur for several months, with a median 3 months, ${ }^{2,18,23}$ even after the revocation of amiodarone. Interestingly, the development of optic disc edema has been reported even weeks after the discontinuation of amiodarone. ${ }^{18}$ Amiodarone in the blood may remain at therapeutic or near-therapeutic levels for extended periods due to its variable and long half-life, ${ }^{18,26}$ averaging 58 but up to 142 days, ${ }^{27}$ and thus is thought to continue to exert a toxic effect on the disc even after drug discontinuation. ${ }^{14,28}$

Table 1: Retinal nerve fiber layer average thickness $(\mu \mathrm{m})$ in each quadrant in the right and left eyes at initial presentation and 1, 2, 2.5, 4, 6 and 8 months from the initial presentation, and final variance in retinal nerve fiber layer thickness ( $\mu m$ ) from the initial evaluation at 8 months.

\begin{tabular}{|c|c|c|c|c|c|c|c|c|}
\hline \multirow{2}{*}{$\begin{array}{l}\text { Interval from } \\
\text { Presentation }\end{array}$} & \multicolumn{4}{|c|}{ Right Eye } & \multicolumn{4}{|c|}{ Left Eye } \\
\hline & Inferior & Superior & Nasal & Temporal & Inferior & Superior & Nasal & Temporal \\
\hline 0 & 105 & 63 & 63 & 50 & 215 & 117 & 134 & 150 \\
\hline 1 month & 107 & 65 & 62 & 44 & 159 & 97 & 149 & 87 \\
\hline 2 months & 98 & 59 & 60 & 39 & 134 & 61 & 100 & 62 \\
\hline 2.5 months & 98 & 63 & 66 & 36 & 107 & 81 & 69 & 72 \\
\hline 4 months & 97 & 56 & 61 & 46 & 108 & 67 & 72 & 64 \\
\hline 6 months & 91 & 59 & 60 & 35 & 77 & 52 & 66 & 49 \\
\hline 8 months & 89 & 59 & 63 & 37 & 70 & 49 & 60 & 45 \\
\hline $\begin{array}{l}\text { Final Variance } \\
\text { From Initial } \\
\text { Presentation }\end{array}$ & -16 & -4 & 0 & -13 & -145 & -68 & -74 & -105 \\
\hline
\end{tabular}

Table 2: Visual field mean deviation $(d B)$ and pattern standard deviation $(d B)$ in the right and left eyes at initial presentation and 1,2, 4 and 8 months from initial presentation, which ultimately remained relatively stable in both eyes over the clinical course.

Visual Field Mean Deviation and Pattern Standard Deviation Progression

\begin{tabular}{|l|c|c|c|c|}
\hline $\begin{array}{l}\text { Interval from } \\
\text { Presentation }\end{array}$ & $\begin{array}{c}\text { Right Eye } \\
\text { Mean Deviation }\end{array}$ & $\begin{array}{c}\text { Right Eye Pattern } \\
\text { Standard Deviation }\end{array}$ & $\begin{array}{c}\text { Left Eye } \\
\text { Mean Deviation }\end{array}$ & $\begin{array}{c}\text { Left Eye Pattern } \\
\text { Standard Deviation }\end{array}$ \\
\hline $\mathbf{0}$ & -5.58 & 3.82 & -7.62 & 5.61 \\
\hline $\mathbf{1}$ month & -8.38 & 5.64 & -6.36 & 2.97 \\
\hline 2 months & -7.22 & 3.97 & -7.66 & 4.74 \\
\hline 4 months & -6.28 & 6.28 & -7.33 & 6.69 \\
\hline 8 months & -5.47 & 3.81 & -8.78 & 6.75 \\
\hline
\end{tabular}

The prognosis varies from some improvement in up to $40-58 \%$ of patients, a decline in acuity in $10-21 \%$, even after amiodarone discontinuation, and permanent visual loss that remains stable compared to presentation in $21 \%$. ${ }^{2,18}$ Acuity worse than 20/200 in at least one eye has been shown in $20 \%$ of those affected. ${ }^{2}$ Visual field loss is generally permanent. ${ }^{18}$ Similar to this case, previous reports have documented a transient increase in retinal nerve fiber layer thickness consistent with acute optic disc edema, followed by progressive axonal loss, as measured by optical coherence tomography, even after the discontinuation of amiodarone..$^{15}$ This axonal loss is appreciated clinically as pallor of the optic disc. ${ }^{14,18,24}$ 
There remains some controversy as to whether amiodarone-associated optic neuropathy is truly an entity distinct from non-arteritic anterior ischemic optic neuropathy, typically its main differential diagnosis, ${ }^{8,14}$ if it is simply a variant, or possibly only a risk factor for it. ${ }^{4,29}$ Non-arteritic anterior ischemic optic neuropathy is thought to be due to ischemia involving the posterior ciliary arteries. ${ }^{30}$ Non-arteritic anterior ischemic optic neuropathy and amiodarone-associated optic neuropathy patients share similar systemic cardiovascular risk factors, ${ }^{31}$ along with similar clinical characteristics such as the appearance of the optic discs and patterns of visual field loss, ${ }^{19,23}$ making the differentiation more difficult. ${ }^{32,33}$ However, there are features of amiodarone-associated optic neuropathy that are atypical of non-arteritic anterior ischemic optic neuropathy, and growing clinical evidence supports that it is a distinct diagnosis. ${ }^{8,34}$

Unlike amiodarone-associated optic neuropathy, non-arteritic anterior ischemic optic neuropathy generally presents acutely (over hours to days, possibly weeks) ${ }^{2,31}$ with severe, ${ }^{35}$ unilateral optic nerve dysfunction, ${ }^{31}$ typically inferior altitudinal visual field defects, ${ }^{31,35-37}$ and acuity ranging from $20 / 20$ to no light perception. ${ }^{38}$ The resolution of disc edema typically occurs over the course of $4-8$ weeks. ${ }^{14,23}$ The incidence in those over 50 years of age has been reported to be $0.01-0.02 \%,{ }^{35,39}$ which is much lower than that reported for amiodarone-associated optic neuropathy. Cases may be bilateral, but are almost universally sequential rather than simultaneous. ${ }^{40}$ Bilateral cases present at a lower rate than that seen in amiodarone-associated optic neuropathy, ${ }^{14}$ as simultaneously bilateral cases are usually associated with sudden arterial hypotension or perioperative hypovolemia. ${ }^{41,42}$

Most (90\%) cases of amiodarone-associated optic neuropathy have been reported in males, ${ }^{18}$ while non-arteritic anterior ischemic optic neuropathy exhibits an equal male-female distribution. ${ }^{2,39}$ Cheng et al. conducted a retrospective population-based cohort study to investigate whether there was an increased risk of optic neuropathy in amiodarone-treated patients, and found a 2-fold increased risk; male amiodarone users had a 3-fold greater risk of optic neuropathy. ${ }^{34}$ Amiodarone-associated optic neuropathy has no predilection for small discs or cup-to-disc ratios, ${ }^{18}$ whereas non-arteritic anterior ischemic optic neuropathy has a nearly exclusive predilection for small optic discs with small cup-to-disc ratios. ${ }^{43}$

Performance on color vision testing may vary depending on the optic nerve's function in any optic neuropathy ${ }^{37}$ but tends to remain normal in ischemic, but abnormal in inflammatory, optic neuropathies. ${ }^{36}$ Miller and Arnold report that loss of color vision in non-arteritic anterior ischemic optic neuropathy tends to parallel that of acuity. ${ }^{31}$ Blue color deficiency has been reported as an early indication of amiodarone-associated optic neuropathy; ${ }^{44}$ thus, color testing may be a helpful tool for assessment and monitoring. In this patient, abnormal color testing results were not used as a functional measure for disease-monitoring because he reported congenital color deficiency with unknown baseline color-discrimination ability.

The direct cause of optic neuropathy due to amiodarone use has not been well established, and thus is not universally accepted. Regarding ocular toxicology, Fraunfelder and Shults assert that there are inadequate data to support amiodarone as a cause of toxic optic neuropathy, ${ }^{29}$ and Younge aptly notes that causation cannot be confirmed without a prospective controlled study, which would be difficult to design.$^{45}$ There are ethical limitations to conducting an ideal prospective, double-masked, randomized, placebo-controlled study, because this would require the withholding of treatment in the placebo control group; however, since amiodarone is used to treat life-threatening cardiac dysrhythmias, withholding treatment would be unethical. ${ }^{8}$ Similarly, positive re-challenge of the drug in cases of optic neuropathy to confirm its causation would also be unethical. Thus, causation remains only strongly speculated.

Mindel et al. undertook a randomized trial investigating amiodarone's role in the prevention of sudden cardiac death, and bilateral vision loss was considered a secondary end-point as a way to explore this entity. Of the 837 subjects using amiodarone, none self-reported bilateral vision loss. ${ }^{25}$ However, patients did not undergo ophthalmic examinations, and this endpoint was reached if subjects reported "yes" to having "optic neuritis." ${ }^{5}$ Therefore, mild, unilateral, peripherally affected, or asymptomatic cases may have gone undetected, and patients may have underreported their visual symptoms due to poor understanding of the investigator's inquiry regarding "optic neuritis."

In the present case, the patient remained visually asymptomatic in the left eye. He presented with symptomatic arcuate inferior visual field loss in the right eye, which could have represented superior optic nerve segment nonarteritic anterior ischemic optic neuropathy prior to the development of, or in conjunction with, amiodarone-asso- 
ciated optic neuropathy; however, it is unlikely that the subsequent optic disc swelling in the right eye represented a sequential unilateral non-arteritic anterior ischemic optic neuropathy. Subsequent non-arteritic anterior ischemic optic neuropathy in the fellow eye was found to occur in $14.7 \%$ of cases by 5 years in a ischemic optic neuropathy decompression trial; ${ }^{46}$ however, subsequent non-arteritic anterior ischemic optic neuropathy in the same eye is much less common, reportedly only up to $6.4 \% .{ }^{47}$ Given that optic disc crowding is a risk factor, the low risk of sequential ipsilateral disease is presumably associated with decompression of the disc as the affected fibers atrophy, though other factors also likely contribute. ${ }^{48}$ This patient's baseline cup-to-disc ratio was unknown, thus the association of non-arteritic anterior ischemic optic neuropathy to small cup-to-disc ratios cannot be confidently applied or excluded; regardless, there is only a very small likelihood of a sequential non-arteritic anterior ischemic optic neuropathy in the same eye in association with sequential or simultaneous visually asymptomatic non-arteritic anterior ischemic optic neuropathy in the fellow eye in this patient. However, it remains possible that the patient had superior segmental non-arteritic anterior ischemic optic neuropathy in his right eye previous to, or co-existing with, the bilateral amiodarone-associated optic neuropathy.

Amiodarone-associated optic neuropathy remains a clinical diagnosis of exclusion, but should be a differential diagnosis with optic neuropathy surrounding use of the drug. Other differential diagnoses include papilledema and other optic neuropathies such as those associated with infectious, inflammatory, infiltrative, compressive, nutritional, metabolic or other toxic sources. ${ }^{5}$ This patient had a lack of pertinent exposures to various infectious causes such as tuberculosis, syphilis, Lyme disease or cat scratch disease, and, in conjunction with his clinical presentation, infectious etiologies were thought unlikely. Further laboratory investigations aside from a rapid plasma reagin to screen for syphilis were not pursued. which represents a limitation of this report.

In cases of bilateral optic disc edema, giant cell arteritis and increased intracranial pressure must be excluded. ${ }^{22}$ This patient initially had a mildly elevated C-reactive protein and erythrocyte sedimentation rate; both can be elevated in giant cell arteritis and numerous other conditions. ${ }^{49}$ The American College of Rheumatology's diagnostic criteria for giant cell arteritis include an erythrocyte sedimentation rate of $50 \mathrm{~mm} /$ hour or more. ${ }^{50}$ Hayreh et al. reported that the "(c)linical criteria most strongly suggestive of giant cell arteritis include jaw claudication, C-reactive protein above $2.45 \mathrm{mg} / \mathrm{dl}$, neck pain, and an erythrocyte sedimentation rate of $47 \mathrm{~mm} /$ hour or more, in that order", and this patient demonstrated none of these. ${ }^{49}$ Also, his platelet count was normal. A platelet count greater than $400 \times 10^{3} / \mu \mathrm{L}$ has been reported as a useful marker to predict that a temporal artery biopsy would be positive for giant cell arteritis, ${ }^{51}$ and thrombocytosis has been reported to be a predictor of an ultimate diagnosis of giant cell arteritis in patients referred for temporal artery biopsies; ${ }^{52}$ this patient's platelet count was well below that threshold. Additionally, he denied systemic symptoms typical of giant cell arteritis, and though it may be isolated without systemic symptoms despite a confirmed positive temporal artery biopsy in some cases, ${ }^{53}$ his central visual acuity was well-preserved in both eyes, which is not consistent with arteritic anterior ischemic optic neuropathy. Additionally, the duration of disc edema without substantial vision loss is not consistent with arteritic ischemic optic neuropathy. These several factors lead to a very low level of suspicion, so temporal artery biopsy was not warranted or pursued.

Papilledema due to increased intracranial pressure was also considered. This patient underwent neuroimaging that ruled out a mass lesion, and the radiologist detected no secondary radiologic evidence of increased intracranial pressure or dural venous sinus thrombosis, such as optic nerve sheath enlargement,${ }^{54}$ flattening of the posterior sclera, ${ }^{55}$ or optic nerve tortuosity. ${ }^{54,56}$ Because of the patient's anti-coagulated state and the low suspicion of increased intracranial pressure, a lumbar puncture was deferred.

\section{CONCLUSIONS}

In this patient, his retinal nerve fiber layer thickness remained roughly stable superiorly and nasally in his right eye over the duration of the clinical course, but already appeared pale at the time of presentation. The inferior and temporal retinal nerve fiber layer thickness dropped by 16 and $13 \mu \mathrm{m}$, respectively, as the inferior edema progressed to become somewhat atrophic. His left eye, which upon initial evaluation had gross optic disc edema, had dramatic relative retinal nerve fiber layer thinning over the clinical course, more blatantly inferiorly $(-145 \mu \mathrm{m})$, then temporally $(-105 \mu \mathrm{m})$, nasally $(-74 \mu \mathrm{m})$ and lastly superiorly $(-68 \mu \mathrm{m})$. FitzGibbon and Taylor reported that, in human retinas, retinal ganglion cell axons tend to be larger on average inferiorly and/or nasally than superiorly and/ or temporally, and that foveal axons are generally smaller than extrafoveal axons. ${ }^{57}$ Interestingly, this case demonstrated more retinal nerve fiber layer loss inferiorly in both eyes, suggesting that the generally larger inferior axons were more significantly affected by this optic neuropathy. In conjunction with Mansour's findings suggesting that 
amiodarone use results in the accumulation of intracytoplasmic lamellar inclusion bodies, particularly in large optic nerve axons, FitzGibbon and Taylor's finding of a variable retinal axonal size distribution may be significant for future investigations of amiodarone-associated optic neuropathy's relative regional optic nerve impact and involvement based on axonal diameter.

Though uncommon, amiodarone use can lead to optic neuropathy, which can cause a permanent loss of visual acuity or field. Symptoms are usually insidious and patients may even be asymptomatic, so detection of optic neuropathy, prior to the development of visual symptoms, would be ideal; color vision testing, a dilated exam and visual fields have great clinical utility in early detection. It is advised that patients be evaluated with a comprehensive eye examination at 4 and 12 months after initiating amiodarone therapy, ${ }^{18}$ and at least annually thereafter. ${ }^{5,18}$

Aside from early detection, it can be difficult to decide upon the appropriate course of action in cases of amiodarone-associated optic neuropathy, particularly in patients who are visually asymptomatic. There is no unanimity regarding whether amiodarone should be discontinued, because there can be varying visual outcomes regardless of whether amiodarone is discontinued, and clearly these patients need to treat their high-risk underlying arrhythmia. ${ }^{4}$ Patient care should be individualized, and consultation with the patient's cardiologist is needed to carefully consider the risks and benefits of amiodarone therapy.

\section{ACKNOWLEDGEMENTS}

The author has no commercial associations or conflicts of interest to disclose.

The information presented in this manuscript does not necessarily reflect the views of the United States Government or of the United States Department of Veterans Affairs.

The author would like to acknowledge Ed Williams from the VA Ann Arbor Healthcare System for his assistance with the editing of images.

CORRESPONDENCE:

Sara Weidmayer

8738 Neal Road

Manchester, MI 48158

Phone: 231-580-9114

Fax: 734-845-3273

saraweidmayer@gmail.com 


\section{REFERENCES}

1. Feiner LA, Younge BR, Kazmier FJ, et al. Optic neuropathy and amiodarone therapy. Mayo Clin Proc 1987;62:702-17.

2. Passman RS, Bennet CL, Purpura JM, et al. Amiodarone-associated optic neuropathy: a critical review. Am J Med 2012;125:447-53.

3. Kaplan LJ, Cappaert WE. Amiodarone keratopathy: correlation to dosage and duration. Arch Ophthalmol 1982;100:601-2.

4. Murphy MA, Murphy JF. Amiodarone and optic neuropathy: the heart of the matter. J Neuroophthalmol 2005;25:232-36.

5. Kervinen M, Falck A, Hurskainen M, Hautala N. Bilateral optic neuropathy and permanent loss of vision after treatment with amiodarone. J Cardiovasc Pharmacol 2013;62:394-6.

6. Santangeli P, Di Biase L, Burkhardt JD, et al. Examining the safety of amiodarone. Expert Opin Drug Saf 2012;11:191-214.

7. Vassallo P, Trohman RG. Prescribing amiodarone: an evidencebased review of clinical indications. JAMA 2007;298:1312-22.

8. Chen D, Hedges T. Amiodarone optic neuropathy-review. Semin Ophthalmol 2009;18:169-73.

9. Greene L, Graham EL, Werner JA, et al. Toxic and therapeutic effects of amiodarone in the treatment of cardiac arrhythmias. J Am Coll Cardiol 1983;2:1114-28.

10. Goldschlager N, Epstein AE, Naccarelli GV, et al. A practical guide for clinicians who treat patients with amiodarone: 2007. Heart Rhythm 2007;4:1250-9.

11. Raeder EA, Podrid PJ, Lown B. Side effects and complications of amiodarone therapy. Am Heart J 1985;109:975-83.

12. Flach AJ, Dolan BJ, Sudduth B, Weddell J. Amiodarone-induced lens opacities. Arch Ophthalmol 1983;101:1554-6.

13. Knudsen A. Short-term treatment with oral amiodarone resulting in bilateral optic neuropathy and permanent blindness. BMJ Case Rep 2017;1-4.

14. Clement CI, Franzco PM, Franzco KPT. Bilateral optic neuropathy due to amiodarone with recurrence. Clin Exp Ophthalmol 2005;33:222-5.

15. Martínez-López-Portillo AM, Martínez-Gamero BO, MohamedNoriega J, et al. Behaviour of disc oedema during and after amiodarone optic neuropathy: case report. J Clin Diagn Res 2014;8:VD04-5.

16. Pepple KL, Bhatti MT, Foroozan R. Not again! Surv Ophthalmol 2011;56:86-93.

17. Shinder R, Frohman LP, Turbin RE. Regression of bilateral optic disc edema after discontinuation of amiodarone. J Neuroophthalmol 2006;26:192-4.

18. Johnson LN, Krohel GB, Thomas ER. The clinical spectrum of amiodarone-associated optic neuropathy. J Natl Med Assoc 2004;96:1477-91.

19. Gittinger JW Jr, Asdourian GK. Papillopathy caused by amiodarone. Arch Ophthalmol 1987;105:349-51.

20. Mansour AM, Puklin JE, O'Grady R. Optic nerve ultrastructure following amiodarone therapy. J Clin Neuroophthalmol 1988;8:231-7.

21. Johnson LN, Krohel GB, Thomas ER. The clinical spectrum of amiodarone-associated optic neuropathy. J Natl Med Assoc 2004;96(11):1477-91.

22. Purvin V, Kawasaki A, Borruat FX. Optic neuropathy in patients using amiodarone. Arch Ophthalmol 2006;124:696-701.

23. Macaluso DC, Shults WT, Fraunfelder FT. Features of amiodaroneinduced optic neuropathy. Am J Ophthalmol 1999;127:610-12.

24. Sharma P, Sharma R. Toxic optic neuropathy. Indian J Ophthalmol 2011;59:137-41.

25. Mindel JS, Anderson J, Johnson G, et al. Absence of bilateral vision loss from amiodarone: a randomized trial. Am Heart $\mathrm{J}$ 2007;153:837-42.

26. Mäntyjärvi M, Tuppurainen K, Ikäheimo K. Ocular side effects of amiodarone. Surv Ophthalmol 1998;42:360-3.

27. Siddoway LA. Amiodarone: guidelines for use and monitoring. Am Fam Physician 2003;68:2189-97.

28. Latini R, Tognoni G, Kates RE. Clinical pharmacokinetics of amiodarone. Clin Pharmacokinet 1984;9:136-56.

29. Fraunfelder FW, Shults T. Non-arteritic anterior ischemic optic neuropathy, erectile dysfunction drugs, and amiodarone: is there a relationship? J Neuroophthalmol 2006;26:1-3.

30. Hayreh SS. Anterior ischemic optic neuropathy. Br J Ophthalmol 1974;58:955-63.
31. Miller NR, Arnold AC. Current concepts in the diagnosis, pathogenesis and management of nonarteritic anterior ischaemic optic neuropathy. Eye 2015;29:65-79.

32. Heyreh SS, Zimmerman MB. Nonarteritic anterior ischemic optic neuropathy: natural history of visual outcome. Ophthalmology 2008;115:298-305e2.

33. Mindel JS. Amiodarone and optic neuropathy. Am Heart J 2008;156:411-13.

34. Cheng H-C, Yen H-J, Huang N, et al. Amiodarone-associated optic neuropathy: a nationwide study. Ophthalmology 2015;122:2553-9.

35. Hattenhauer MG, Leavitt JA, Hodge DO, et al. Incidence of nonarteritic anterior optic neuropathy. Am J Ophthalmol 1997;123:103-7.

36. Rizzo JF III, Lessell S. Optic neuritis and ischemic optic neuropathy. Arch Ophthalmol 1991;109:1668-72.

37. Biousse V, Newman NJ. Diagnosis and clinical features of common optic neuropathies. Lancet Neurol 2016;15:1355-67.

38. Repka MX, Savina PJ, Schatz NJ, Sergott RC. Clinical profile and long term implications of anterior ischaemic optic neuropathy. Am J Ophthalmol 1983;96:478-83.

39. Johnson LN, Arnold AC. Incidence of nonarteritic and arteritic anterior ischemic optic neuropathy: population-based study in the State of Missouri and Los Angeles County, California. J Neuroophthalmol 1994;14:38-44

40. Gundogan FC, Guven S, Yolcu U, et al. Bilateral simultaneous nonarteritic anterior ischaemic optic neuropathy: case report. Neuroophthalmology 2013;37:214-9.

41. Basile C, Addabbo G, Montanaro A. anterior ischemic optic neuropathy and dialysis: role of hypotension and anemia. J Nephrol 2001;14:420-3.

42. Kaeser PF, Borruat FX. Vision loss after orthopedic procedures. J Arthroplasty 2011;26(2):338.e17-9.

43. Beck RW, Servais GE, Hayreh SS. Anterior ischemic optic neuropathy. IX. Cup-to-disc ratio and its role in pathogenesis. Ophthalmology 1987;94:1503-8.

44. Ikäheimo K, Kettunen R, Mäntyjärvi M. Visual functions and adverse ocular effects in patients with amiodarone medication. Acta Ophthalmol Scand 2002;80:59-63.

45. Younge BR. Amiodarone and ischemic optic neuropathy. J Neuroophthalmol 2007;27:85-6.

46. Newman NJ, Scherer R, Langenberg P, et al. The fellow eye in NAION: Report from the Ischemic Optic Neuropathy Decompression Trial Follow-Up Study. Am J Ophthalmol 2002;134: 317-28.

47. Hayreh SS, Podhajsky PA, Zimmerman B. ipsilateral recurrence of nonarteritic anterior ischemic optic neuropathy. Am J Ophthalmol 2001;132:734-42.

48. Heyreh S. Blood supply of the optic nerve head and the evaluation of it: myth and reality. Prog Retin Eye Res 2001;20:563.

49. Hayreh SS, Podhajsky PA, Raman R, Zimmerman B. Giant cell arteritis: validity and reliability of various diagnostic criteria. Ophthalmology 1997;123:285-96.

50. Hunder GG, Bloch DA, Michel BA, et al. The American College of Rheumatology 1990 Criteria for the Classification of Giant Cell Arteritis. Arthritis Rheum 1990;33:1122-8

51. Foorzan R, Danesh-Meyer H, Savina PJ, et al. Thrombocytosis in patients with biopsy-proven giant cell arteritis. Ophthalmol 2002;109:1267-71.

52. Grossman C, Barshack I, Koren-Morag N, et al. Baseline clinical predictors of an ultimate giant cell arteritis diagnosis in patients referred to temporal artery biopsy. Clin Rheumatol 2016;35:1817-22.

53. Hayreh SS, Podhajsky PA, Zimmerman B. Occult giant cell arteritis: ocular manifestations. Am J Ophthalmol 1998;125:521-6.

54. Brodsky MC, Vaphiades M. Magnetic resonance imaging in pseudotumor cerebri. Ophthalmology 1998;105:1686-93.

55. Jacobson DM. Intracranial hypertension and the syndrome of acquired hyperopia with choroidal folds. J Neuroophthalmol 1995;15:178-85.

56. Passi N, Degnan AJ, Levy LM. MR Imaging of papilledema and visual pathways: effects of increased intracranial pressure and pathophysiologic mechanisms. Am J Neuroradiol 2013;34:919-24.

57. FitzGibbon T, Taylor SF. Mean retinal ganglion cell axon diameter varies with location in the human retina. Jpn J Ophthalmol 2012;56:631-7. 